\title{
Role of Serum Carrier Proteins in the Peripheral Metabolism and Tissue Distribution of Thyroid Hormones in Familial Dysalbuminemic Hyperthyroxinemia and Congenital Elevation of Thyroxine-binding Globulin
}

\author{
Romano Bianchi, Giorgio lervasi, Alessandro Pilo, Frantisek Vitek, \\ Marco Ferdeghini, Franco Cazzuola, and Gianfranco Giraudi \\ National Research Council (CNR) Institute of Clinical Physiology, and Cattedra di Patologia Speciale Medica V, \\ University of Pisa, Pisa, Italy; Institute of Biophysics, Charles University, Prague, Czechoslovakia; \\ and Institute for Analytical Chemistry, University of Turin, Turin, Italy
}

\begin{abstract}
To investigate the role of thyroxine-binding globulin (TBG) and albumin in the availability of thyroid hormones to peripheral tissues, comprehensive kinetic studies of thyroxine $\left(T_{4}\right)$ and triiodothyronine $\left(\mathrm{T}_{3}\right)$ were carried out in eight subjects with familial dysalbuminemic hyperthyroxinemia (FDH), in four subjects with inherited TBG excess, and in 15 normals. In high-TBG subjects, the reduction of $T_{4}$ and $T_{3}$ plasma clearance rates (by $51 \%$ and $54 \%$, respectively) was associated with normal daily productions; $T_{4}$ and $T_{3}$ distribution volumes were significantly reduced. In FDH subjects $T_{4}$ clearance was less reduced (by $31 \%$ ) than in high TBG; consequently $T_{4}$ production rate was significantly increased (by $42 \%$ ); $T_{4}$ and $T_{3}$ distribution volumes and $T_{3}$ clearance rate were unchanged. Increased $T_{3}$ peripheral production in FDH (by $24 \%$ ) indicates that $T_{4}$ bound to abnormal albumin is more available to tissues than $T_{4}$ carried by $T B G$, thus suggesting an important role of albumin in $T_{4}$ availability to the periphery.
\end{abstract}

\section{Introduction}

Familial dysalbuminemic hyperthyroxinemia (FDH) ${ }^{1}$ and familial elevation of thyroxine-binding globulin (TBG) are two hereditary abnormalities of the interaction between thyroid hormones and their binding proteins, both leading to euthyroid hyperthyroxinemia (1-7). In the former, the serum thyroid hormone excess is due to an albumin molecule with an abnormal binding site having a much greater affinity for thyroxine $\left(\mathrm{T}_{4}\right)$; in the latter, hyperthyroxinemia is due to an increased serum concentration of TBG. Absolute $T_{4}$ and triiodothyronine $\left(T_{3}\right)$

This work was presented in part at the Ninth International Thyroid Congress, Sao Paulo, Brazil, 1-6 September 1985.

Address reprint requests to Dr. Bianchi, CNR Institute of Clinical Physiology, Via Savi, 8, 56100 Pisa, Italy.

Received for publication 7 July 1986 and in revised form 30 December 1986.

1. Abbreviations used in this paper: $\mathrm{CR}$, conversion ratio; FCR, fractional catabolic rate; FDH, familial dysalbuminemic hyperthyroxinemia; IDV, initial distribution volume; $\mathrm{MC}$, multicompartmental; MCR, plasma (or metabolic) clearance rate; NC, noncompartmental; $Q_{t}$, total extrathyroidal body pool; $\mathrm{rT}_{3}$, reverse triiodothyonine; $\mathrm{SR}$, secretion rate; $\mathrm{T}_{3}$, triiodothyronine; $\mathrm{T}_{4}$, thyroxine; TBG, thyroxine-binding globulin; TDV, total distribution volume; TR, transfer rate.

J. Clin. Invest.

(c) The American Society for Clinical Investigation, Inc.

$0021-9738 / 87 / 08 / 0522 / 13 \$ 2.00$

Volume 80, August 1987, 522-534 serum free concentrations are, however, normal in both conditions. Although it is widely recognized that only the unbound hormone fraction is available to enter tissues, some experimental evidence suggests that also a portion of albumin-bound $T_{4}$ is readily available for transport $(8,9)$. In contrast, more recent studies in FDH (10) and in rats injected in the portal vein with serum from FDH subjects (11), have ruled out a specific role for albumin, different from TBG, in the transport of $T_{4}$ into cells. It should be noted that this conclusion has been based on $T_{4}$ kinetic studies, whereas the data on $T_{3}$ kinetics are few and incomplete (1).

Because most of the circulating $T_{3}$ normally arises from $T_{4}$ to $T_{3}$ conversion in peripheral tissues rather than from direct thyroidal secretion, we carried out simultaneous $T_{4}$ and $T_{3}$ turnover studies in subjects with altered thyroid hormone-binding protein interaction, aiming at a further definition of the role of TBG and albumin in the transport and distribution of thyroid hormones. Both noncompartmental and multicompartmental methods were used for data analysis. The latter approach appears to be particularly useful inasmuch as it allows estimating the partition of extrathyroidal hormones among the various tissues and measuring the unbiased $T_{3}$ production rate $(P R)$ and the total body $T_{3}$ pool $\left(Q_{t}\right)$ and a direct in vivo quantification of the $T_{3}$ thyroidal secretion rate (SR). The overall $T_{4}$ to $T_{3}$ conversion ratio (CR), and the relative contribution to peripheral $T_{3}$ neogenesis of the "fast or slow" exchanging tissue pools can also be assessed when using a multicompartmental description of the thyroid hormone system. The noncompartmental analysis, in contrast, was also used to compare the kinetic results of the present study with those previously reported.

\section{Methods}

\section{Subjects, protocol, and analytical procedures}

A total of 28 turnover studies were performed: eight subjects from five families with FDH, four men and four women, ranging in age 31-71 yr; four women from three families with congenital elevation of TBG, aged 48-67 yr. 15 normal subjects, 10 men and 5 women, served as the control group. All subjects were euthyroid by clinical and laboratory data (Table I). Measurements of total $T_{4}$, total $T_{3}$, thyrotropin (TSH), and reverse $\mathrm{T}_{3}\left(\mathrm{rT}_{3}\right)$ in the serum were performed by specific radioimmunoassays (RIA) as previously reported (12). Total $T_{4}$ and total $T_{3}$ serum concentrations were also measured after extraction with ethanol-butanol 1:1 to rule out the possibility that the abnormal serum albumin in FDH interferes in the RIA to yield artifactually high values. Free $T_{3}$ was measured by Liso-Phase RIA (Sclavo, Milan, Italy); TBG was measured by ImmoPhase (Corning Medical, Medfield, MA). The percentages of free thyroxine were measured by equilibrium dialysis using a modification of the method of Sterling and Brenner $(13,14)$. Serum concentrations of thyroxine-binding prealbumin and albumin were measured by radial 
immunodiffusion (Behring, Berlin, Federal Republic of Germany). Thyrotropin-releasing hormone (TRH) stimulation tests were performed by intravenous bolus injection of $200 \mu \mathrm{g}$ of TRH (Biodata, Milan). The distribution of tracer concentrations of ${ }^{125} \mathrm{I}_{-} \mathrm{T}_{4}$ among serum carrier proteins of subjects with FDH was determined by polyacrylamide gel electrophoresis in Tris glycine buffer, $\mathrm{pH} 8.9$ (15).

Informed consent was obtained from each subject before the tracer experiment. All subjects received 10 drops of saturated potassium iodide solution per day, starting $2 \mathrm{~d}$ before, throughout the study. ${ }^{125} \mathrm{I}-\mathrm{T}_{4}$ (calculated sp act $200 \mu \mathrm{Ci} / \mu \mathrm{g}$ ) and ${ }^{131} \mathrm{I}-\mathrm{T}_{3}$ (sp act $240 \mu \mathrm{Ci} / \mu \mathrm{g}$ ) were prepared in our laboratory by the chloramine-T technique using a labeling procedure described previously (16). A measured dose containing ${ }^{125} \mathrm{I}_{-} \mathrm{T}_{4}$ $(50 \mu \mathrm{Ci})$ and ${ }^{131} \mathrm{I}-\mathrm{T}_{3}(30 \mu \mathrm{Ci})$ was injected intravenously as a single bolus. Venous blood samples were taken at frequent intervals for the first 24 $\mathrm{h}(0.08,0.25,0.5,0.75,1,2,4,8,12,18,24 \mathrm{~h})$, then every $12,24 \mathrm{~h}$ until 144-192 $\mathrm{h}$ after injection, and the plasma disappearance curves of ${ }^{125} \mathrm{I}$ $\mathrm{T}_{4}$ and ${ }^{131} \mathrm{I}-\mathrm{T}_{3}$ and concentrations of ${ }^{125} \mathrm{I}-\mathrm{T}_{3}$ newly formed from $5^{\prime}$-monodeiodination of tracer ${ }^{125} \mathrm{I}_{-} \mathrm{T}_{4}$ were determined by a chromatographic system using Sephadex G-25 (Superfine, Pharmacia, Uppsala, Sweden) as previously described (12). This method allows quantitative recovery and complete separation of labeled $T_{4}$ and $T_{3}$ from their labeled metabolites.

\section{Binding studies}

Measurement of thyroxine binding to TBG. TBG was separated from other $\mathrm{T}_{4}$-binding proteins by adsorption of the serum glycoprotein fraction on concanavalin A-Sepharose 4B (Con A-Sepharose) $(17,18) .100 \mu \mathrm{l}$ of $\mathrm{T}_{4}$-free serum (diluted 1:20 with phosphate-buffered saline [PBS]) was added to several test tubes containing $200 \mu$ l of a slurry of Con A-Sepharose previously washed and diluted (1:1) with PBS $(0.01 \mathrm{M}$ phosphate buffer, $0.15 \mathrm{M} \mathrm{NaCl}, \mathrm{pH}$ 7.4). The mixture was incubated for $30 \mathrm{~min}$ at room temperature with frequent mixing, and then allowed to settle. The supernatant was discarded and the gel sediment was washed twice with $1 \mathrm{ml}$ of PBS. The gel was then reacted with $1 \mathrm{ml}$ of a variable amount of unlabeled $\mathrm{T}_{4}$ and ${ }^{125} \mathrm{I}-\mathrm{T}_{4}$ in a water bath at $37^{\circ} \mathrm{C}$ for $1 \mathrm{~h}$, with frequent mixing. The mixture was allowed to settle for another hour, then the supernatant was carefully aspirated and the sediment was counted in a gamma counter. Binding data were analyzed according to Scatchard (19) after correction for nonspecific binding.

Measurement of $T_{4}$ binding to albumin. Serum albumin was separated from other $\mathrm{T}_{\mathbf{4}}$-binding proteins by affinity chromatography on Cibacron Blue F3GA immobilized on agarose (Blue Sepharose) (20), after removal of TBG by adsorption on Con A-Sepharose. Briefly, $100 \mu \mathrm{l}$ of whole serum was applied to a microcolumn of Con A-Sepharose $(2 \times 0.9 \mathrm{~cm})$ equilibrated with PBS, and eluted with $2 \mathrm{ml}$ of buffer. The eluate was then applied to a column of Blue Sepharose $(2 \times 0.9 \mathrm{~cm})$, and the albumin was eluted with $1.5 \mathrm{M} \mathrm{NaCl}$ in buffer. The albumin fraction was diluted 1:5 with PBS to lower its salt content. Binding of $T_{4}$ to albumin was assessed by a modification of the competitive binding technique employing Sephadex G-25 (21). $100 \mu$ l of the diluted albumin fraction was added to several test tubes each containing $200 \mathrm{mg}$ of Sephadex G-25 (medium) preequilibrated with PBS. A variable amount of a solution of unlabeled $T_{4}$, tracer ${ }^{125} I-T_{4}$, and PBS were added to the tubes to a final volume of $1.5 \mathrm{ml}(1.0 \mathrm{ml}$ in the excluded volume) and allowed to equilibrate for $1 \mathrm{~h}$ at $37^{\circ} \mathrm{C}$ with frequent mixing, and then, after settling for another hour, $200 \mu l$ of the supernatant was counted. Separate experiments were performed in the same range of $T_{4}$ concentrations but without serum proteins to estimate $T_{4}$ binding by Sephadex. The calculation of the albumin-bound $\mathrm{T}_{4}$ was performed according to the original procedure (21), and the binding data were analyzed by the Scatchard method.

\section{Kinetic studies}

Noncompartmental approach. Standard noncompartmental (NC) formulas (22-24) were used to analyze the plasma disappearance curves of ${ }^{125} \mathrm{I}-\mathrm{T}_{4}$ and of ${ }^{131} \mathrm{I}-\mathrm{T}_{3}$. The following turnover and distribution parameters were computed for both $T_{4}$ and $T_{3}$ kinetics: plasma (or metabolic) clearance rate (MCR), initial distribution volume (IDV), total distribution volume (TDV), production rate (PR), total extrathyroidal pool $\left(Q_{t}\right)$, and fractional catabolic rate (FCR). $F C R=M C R / T D V=P R / Q_{t}$.

The values of the areas and first-order moments of the disappearance curves to be used in NC formulas were computed starting from intercepts and slopes of multiexponential functions (sums of three exponentials), fitted (by least squares) on the experimental plasma ${ }^{125} \mathrm{I}_{-} \mathrm{T}_{4}$ and ${ }^{131}{ }^{\mathrm{I}}-\mathrm{T}_{3}$ data.

The plasma appearance curve of ${ }^{125} \mathrm{I}-\mathrm{T}_{3}$ generated in vivo from the injected ${ }^{125} \mathrm{I}-\mathrm{T}_{4}$ was used to estimate the $T_{4}$ to $T_{3}$ conversion ratio (CR) using a convolution approach previously described $(12,25,26)$. The peripheral production rate of $T_{3}$ was then obtained as the product of the $T_{4}$ production rate by the $T_{4}$ to $T_{3} C R$ (after correction for the $T_{3} / T_{4}$ molecular weight ratio); the thyroidal $T_{3}$ secretion rate $\left(T_{3} S R\right)$ was obtained as the difference between the total $T_{3}$ production rate $\left(T_{3} P R\right)$ and the peripheral $T_{3}$ production rate.

Multicompartmental approach. The assumptions and limitations of the NC approach have been previously discussed in detail $(26,27)$. In brief, the NC approach relies on the assumption that both the production and the disposition of the tracer take place in the central (plasma) pool. This assumption is somewhat in contrast with available physiological information on thyroid hormones; in fact, both $T_{3}$ and $T_{4}$ are known to be metabolized in peripheral tissues where a large fraction of $T_{3}$ is produced from $\mathrm{T}_{4}$ conversion. Therefore, a multicompartmental (MC) model was also used to analyze the same kinetic data. It consists of two mammillary systems, each having a central, a fast, and a slowly exchanging pool (see Fig. 1). The model is essentially that proposed by Di Stefano et al. (28) to which reference is made for tentative anatomical identification of the compartments (28). This MC model is physiologically more meaningful because it takes into proper account the peripheral degradation of $T_{3}$ and $T_{4}$, and the peripheral production of $T_{3}$. Information may also be obtained regarding the subdivision of the extravascular hormone pool into its fast and slowly exchanging segments. It can be predicted from the theory that the values for thyroidal secretion rates of both $T_{4}$ and $T_{3}$ and for their initial distribution pools are identical whether computed by NC or MC analysis. In contrast, the peripheral production rate of $T_{3}$ and the extravascular pools of both $T_{4}$ and $T_{3}$ are underestimated by NC analysis.

A limitation of $\mathrm{MC}$ analysis is that neither the three-compartment model of $T_{4}$ nor that of $T_{3}$ can be uniquely identified from the respective plasma disappearance curves of tracer hormones. To overcome this difficulty, we used the quasi-identification approach put forward by $\mathrm{Di}$ Stefano et al. (28), whereby the model parameters are defined through intervals (bounds) derived from inequalities written on the basis of the model equations. In particular, we used the midpoint of the intervals defined by the inequalities reported by Di Stephano (28) for k21 $\left(\mathrm{T}_{4}\right.$ system) and k54 ( $T_{3}$ system, see Fig. 1). Starting from slopes and intercepts of multiexponential functions best fitted on the experimental plasma disappearance curves of labeled $T_{4}$, we obtained narrow ranges for $k_{21}$ (mean 3.0\%, range 1.6-4.6\%), very similar to those found in $\mathrm{T}_{4}$ kinetic studies in rats (28). Consequently, these interval estimates were judged suitable to identify the three-pool model for $T_{4}$ in humans. The same approach applied to $T_{3}$ disappearance curves of our normal subjects produced relatively large ranges for $\mathrm{k} 54$, (mean $15.8 \%$, range $8.1-42.5 \%$ ) in contrast with the data reported by Di Stefano et al. for $T_{3}$ kinetics in rats (29). For this reason, this approach was not considered to be sufficiently accurate to describe $T_{3}$ kinetics in humans (30). Moreover, the same approach does not yield reasonable interval estimates for the rates of $T_{3}$ production from $T_{4}$ conversion, because the parameters $k 52$ and k63 cannot be estimated individually but only in the combinations (k02 $+\mathrm{k52})$ and (k03 $+\mathrm{k63})$, which are the cumulative outputs from the peripheral $\mathrm{T}_{4}$ pools. In fact, the conversion ratio, computed in cardiac patients according to this method, was determined within rather large bounds $(67 \%$ on average) $(30)$.

To obtain narrower interval estimates for the parameters of $T_{3}$ kinetics, we exploited the experimental data of the appearance curve of labeled $\mathrm{T}_{3}$ generated in vivo from the conversion of the injected labeled $T_{4}$. In our approach, the best fit of this latter experimental curve with 


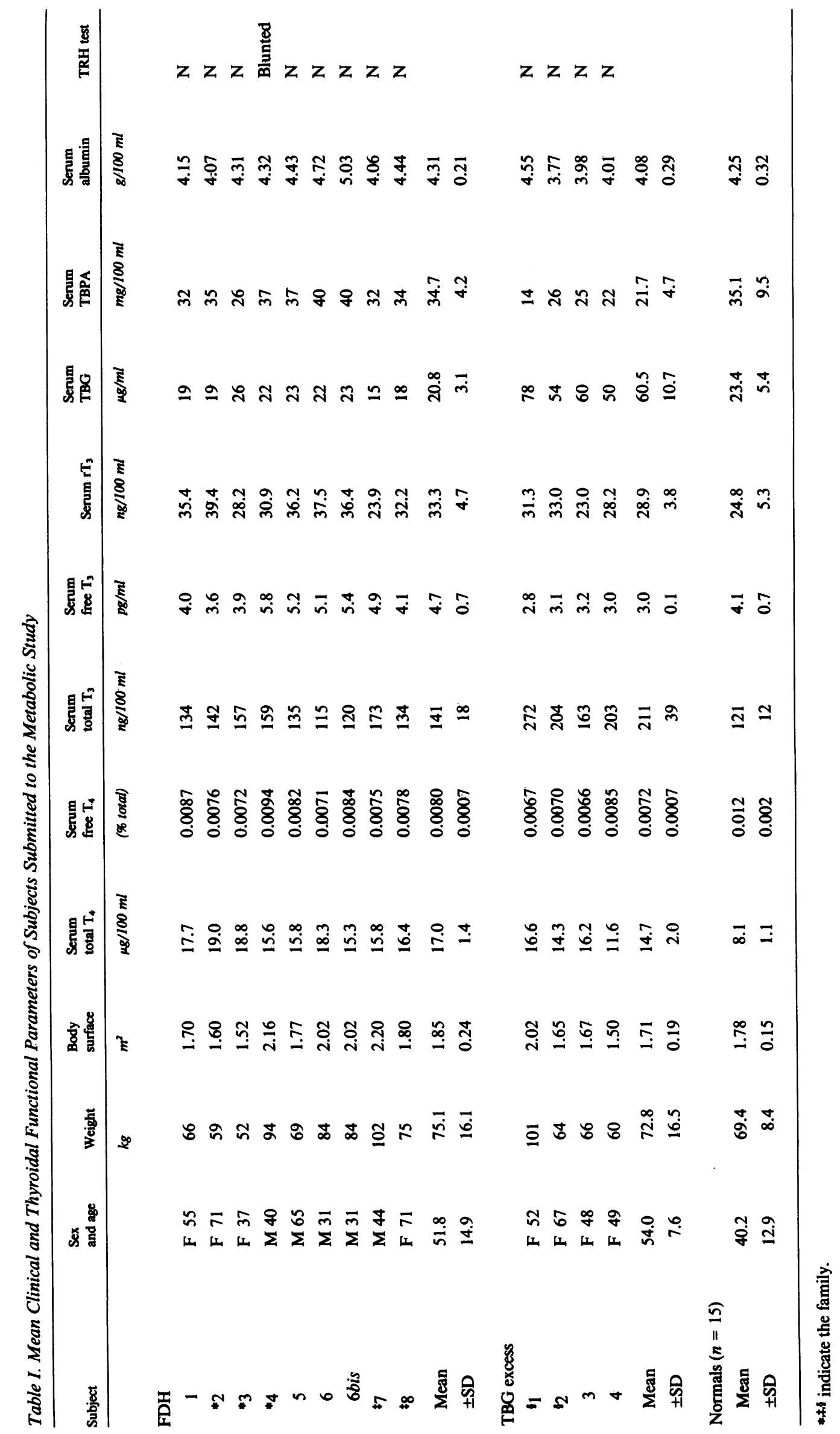


the theoretical curve computed on the basis of the complex six-pool model allowed the computation of the products $\mathrm{k} 45 \times \mathrm{k} 52$ and $\mathrm{k} 46 \times \mathrm{k} 63$. These products are associated with the pathways through which the $T_{3}$ generated from $T_{4}$ deiodination in the fast or the slow pool reaches the sampling compartment (compartment 4). This additional datum allows computing the thyroidal $T_{3}$ secretion rate and to constrain the parameters of $T_{3}$ kinetics within narrower bounds. In particular, the $T_{3}$ production rate in our normal subjects could be determined within intervals of $6 \%$ on the average (range $1.0-8.8 \%$ ) whereas the $T_{4}$ to $T_{3}$ conversion ratio was obtained with bounds of $8.1 \%$ (range $0.6-17.8 \%$ ).

The computed kinetic parameters of the complex six-pool model are reported in this paper as mean population values (see Fig. 8); note that, although thyroidal secretion rates of $T_{4}$ and $T_{3}$ and the masses of central pools of $T_{4}$ and $T_{3}$ are directly identified, all the other parameters are reported as the midpoints of their computed bounds.

\section{Statistical analysis}

Values are given as mean \pm standard deviation or standard error of the mean. Student's $t$ test was used to compare population means.

\section{Results}

\section{Binding studies}

The diphasic Scatchard plot obtained in the binding studies of albumin in FDH subjects pointed out the occurrence of two classes of binding sites. Affinity constants $\left(K_{\mathrm{a}}\right)$ and binding site concentrations calculated from these plots for the high-affinity sites were assumed to represent the affinity and the molar concentration of the abnormal albumin.

The mean values of the measured $\mathrm{T}_{4}$ affinity constant of albumin and TBG binding sites in FDH and in high-TBG sub- jects are reported in Table II. The $\mathrm{T}_{4} K_{\mathrm{a}}$ of abnormal albumin in FDH subjects $\left(4.4 \pm 1.5 \times 10^{6}\right.$ liters $\left./ \mathrm{mol}\right)$ was 12.5 times higher than that of normal albumin, but still much lower $(\sim 1,000$ fold) than that of TBG $\left(4.3 \pm 0.8 \times 10^{9}\right.$ liters $\left./ \mathrm{mol}\right)$. The observed values measured for $\mathrm{T}_{4} K_{\mathrm{a}}$ of TBG and serum albumin are in good agreement with those measured by this and other techniques previously reported (31-33). Tracer ${ }^{125} \mathrm{I}_{-} \mathrm{T}_{4}$ distribution among carrier proteins in normals and FDH subjects is depicted in Fig. 2. In FDH the percentage of $\mathrm{T}_{4}$ carried by albumin $(41.2 \pm 6.3 \%)$ was significantly increased and, consequently, the percentage of $\mathrm{T}_{4}$ carried by TBG was significantly decreased ( $P$ $<0.001)$. These data are in good agreement with those reported previously $(4,10)$.

\section{Kinetic studies}

The mean plasma curves obtained in the three study groups for ${ }^{125} \mathrm{I}_{-} \mathrm{T}_{4}$ and ${ }^{131} \mathrm{I}-\mathrm{T}_{3}$ are depicted in Fig. 3 together with the corresponding fitting functions. It can be seen that the disappearance curve of labeled $T_{4}$ of high-TBG subjects is slower than that of the controls, whereas the curve of FDH subjects is intermediate between the two. The plasma $T_{3}$ disappearance curves of normals and FDH subjects are virtually superimposable, whereas highTBG subjects exhibit a remarkably slower decay rate. Fig. 4 shows the plasma appearance curves, in normals and FDH subjects, of ${ }^{125} \mathrm{I}-\mathrm{T}_{3}$ newly formed in peripheral tissues (by 5 -monodeiodination of labeled $\mathrm{T}_{4}$ ) together with the corresponding fitting functions computed by convolution analysis. The appearance curve of ${ }^{125} \mathrm{I}_{-} \mathrm{T}_{3}$ in FDH subjects is clearly delayed in comparison to that observed in the controls.

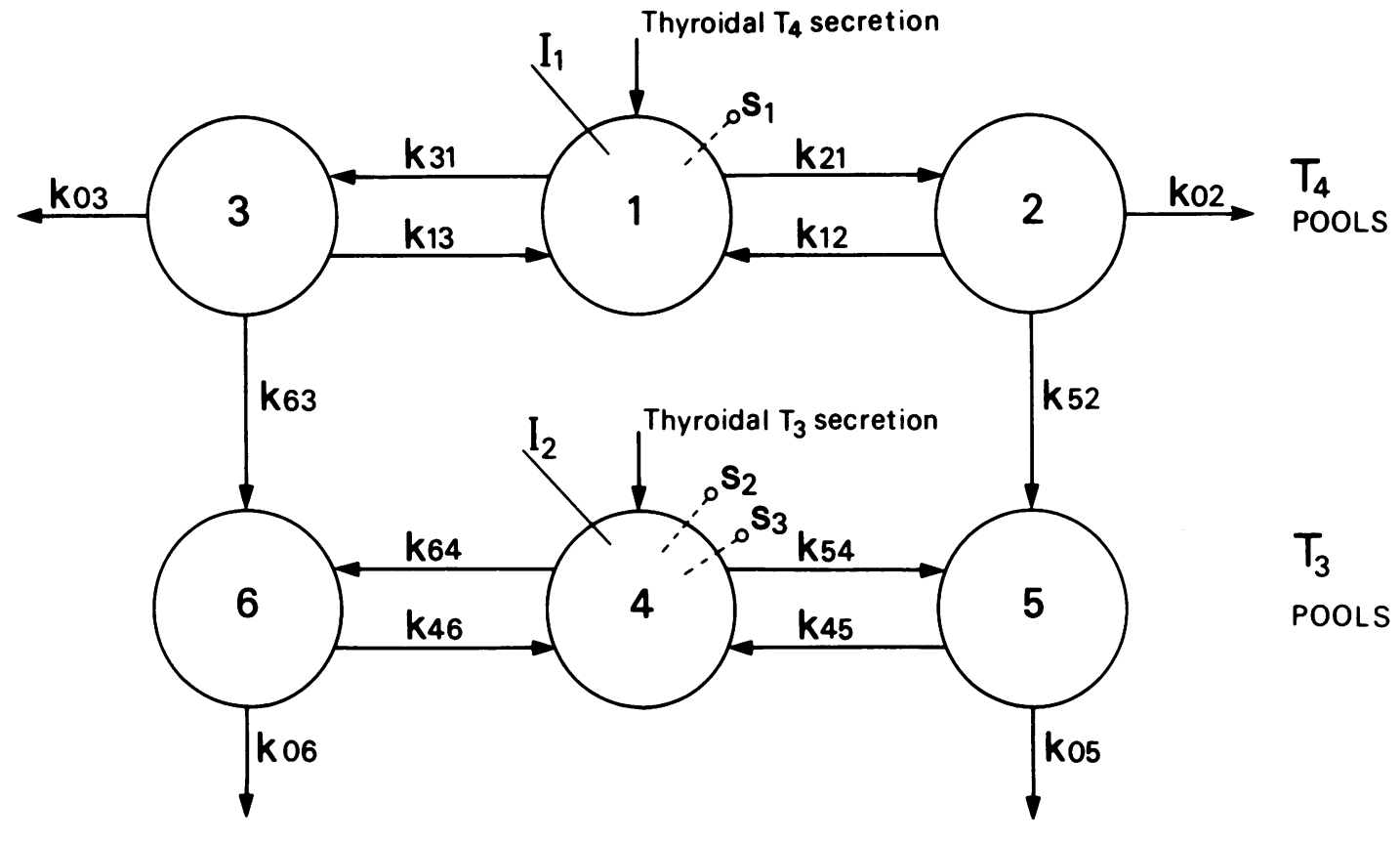

\section{'SLOW' POOLS}

INITIAL DISTRIBUTION

OR 'PLASMA' POOLS

Figure 1. Complex six-compartment model of thyroid hormone kinetics: both $T_{4}$ and $T_{3}$ systems are modeled by three-compartment model interconnected by pathways relative to the conversion of $T_{4}$ into $T_{3}$ (fractional rates k52 and k63). Also indicated in the scheme are the simultaneous tracer inputs $\left(I_{1}\right.$, pulse injection of ${ }^{125} \mathrm{I}_{-} \mathrm{T}_{4} ; \mathrm{I}_{2}$, pulse injec-

\section{'FAST' POOLS}

tion of $\left.{ }^{131} \mathrm{I}-\mathrm{T}_{3}\right)$ and the sampling sites of the three experimentally measured curves $\left(S_{1}\right.$, plasma concentration of ${ }^{125} \mathrm{I}-\mathrm{T}_{4} ; \mathrm{S}_{2}$, plasma concentration of ${ }^{131} \mathrm{I}-\mathrm{T}_{3} ; \mathrm{S}_{3}$, plasma concentration of ${ }^{125} \mathrm{I}-\mathrm{T}_{3}$ generated in vivo). 
Table II. Measured Affinity Constants (Ka) of Serum Carrier Proteins for Thyroxine $\left(37^{\circ} \mathrm{C}, \mathrm{pH} 7.4\right.$; Ionic Strength $\left.0.15 \mathrm{M}\right)$

\begin{tabular}{|c|c|c|c|c|}
\hline Subjects & $K_{\mathrm{a}}$ TBG & $K_{\mathrm{a}}$ HSA & $K_{\mathrm{a}}$ aHSA ${ }^{*}$ & aHSA \\
\hline & liters/mol & liters/mol & liters $/ \mathrm{mol}$ & \% $H S A^{\ddagger}$ \\
\hline \multicolumn{5}{|c|}{ FDH $(n=8)$} \\
\hline Mean & $4.3 \times 10^{9}$ & $3.5 \times 10^{5}$ & $4.4 \times 10^{6}$ & 20.4 \\
\hline$\pm \mathrm{SD}$ & 0.8 & 1.5 & 1.5 & 2.6 \\
\hline \multicolumn{5}{|c|}{$\begin{array}{r}\text { TBG excess } \\
(n=4)\end{array}$} \\
\hline Mean & $3.9 \times 10^{9}$ & $4.5 \times 10^{5}$ & - & - \\
\hline$\pm \mathrm{SD}$ & 1.2 & 1.8 & & \\
\hline
\end{tabular}

" aHSA, serum albumin with "abnormal site"

$\ddagger \%$ aHSA, abnormal serum albumin as percentage of total serum albumin.

NONCOMPARTMENTAL ANALYSIS (TABLE III)

FDH subjects. Mean values of total $\mathrm{T}_{4}$ and total $\mathrm{T}_{3}$ serum concentrations in unextracted sera $(17.0 \pm 1.4 \mu \mathrm{g} / 100 \mathrm{ml}$ and $141 \pm 18$ $\mathrm{ng} / 100 \mathrm{ml}$, respectively) were virtually identical to those measured after ethanol-butanol extraction when corrected for extraction recovery of $64.5 \pm 0.75 \%$ and $84.3 \pm 0.4 \%$, respectively. This finding is in agreement with the data previously reported by Stockigt et al. (3).

$\mathrm{T}_{4} \mathrm{MCR}\left(0.47 \pm 0.12\right.$ liters $/ \mathrm{d}$ per $\left.\mathrm{m}^{2}\right)$ was significantly reduced in comparison to normal subjects $\left(0.68 \pm 0.12\right.$ liters $/ \mathrm{d}$ per $\mathrm{m}^{2}, P$

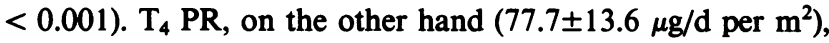
was significantly increased $(P<0.001)$, because total circulating $\mathrm{T}_{4}$ was increased more than its MCR was reduced. It is noteworthy that the total serum $\mathrm{T}_{4}$ concentrations of our FDH patients varied over a wider range $(15.3-19 \mu \mathrm{g} / 100 \mathrm{ml})$ than previously reported $(1,10)$. Moreover, a highly significant, inverse correlation was observed between $\mathrm{T}_{4} \mathrm{MCR}$ and total $\mathrm{T}_{4}$ concentration ( $r=0.96 ; P<0.001$, Fig. 5). To provide a better comparison between our findings and those of Henneman et al. (1) and of Mendel and Cavalieri (10), our FDH patients were subdivided according to whether their $\mathrm{T}_{4}$ concentrations were lower (subgroup A) or higher (subgroup B) than $17 \mu \mathrm{g} / 100 \mathrm{ml}$. In the high- $T_{4}$ subgroup (B) (cases 1, 2, 3, and 6; total $T_{4}$ $=18.5 \pm 0.56 \mu \mathrm{g} / 100 \mathrm{ml}$, Table III), $\mathrm{T}_{4} \mathrm{PR}(63.3 \pm 3.31 \mu \mathrm{g} / \mathrm{d}$ per $\mathrm{m}^{2}$ ) was slightly but not significantly increased in comparison to the control group (Fig. 6). In contrast, $T_{4}$ PR (89.5 \pm 3.56 $\mu \mathrm{g} / \mathrm{d}$ per $\mathrm{m}^{2}$ ) was significantly increased (by $66 \%, P<0.001$ ) in FDH subjects with lower total $\mathrm{T}_{4}$ serum concentration (cases 4 , 5, 6bis, 7, and 8; total $\mathrm{T}_{4}=15.8 \pm 0.37 \mu \mathrm{g} / 100 \mathrm{ml}$, subgroup A).

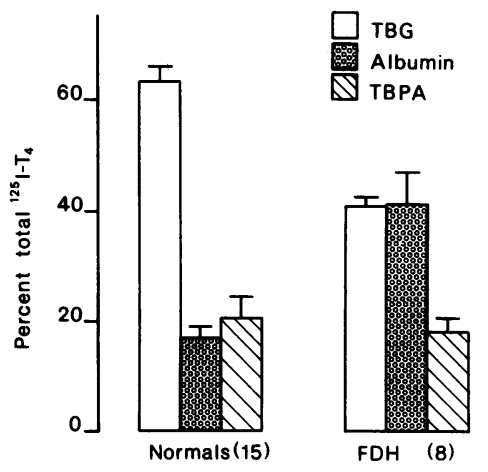

Figure 2. Distribution of ${ }^{125} \mathrm{I}-\mathrm{T}_{4}$ among carrier proteins in serum from 15 euthyroid controls and 8 patients with familial dysalbuminemic hyperthyroxinemia. TBPA, thyroxine-binding prealbumin. Values are means; bars denote standard deviation.

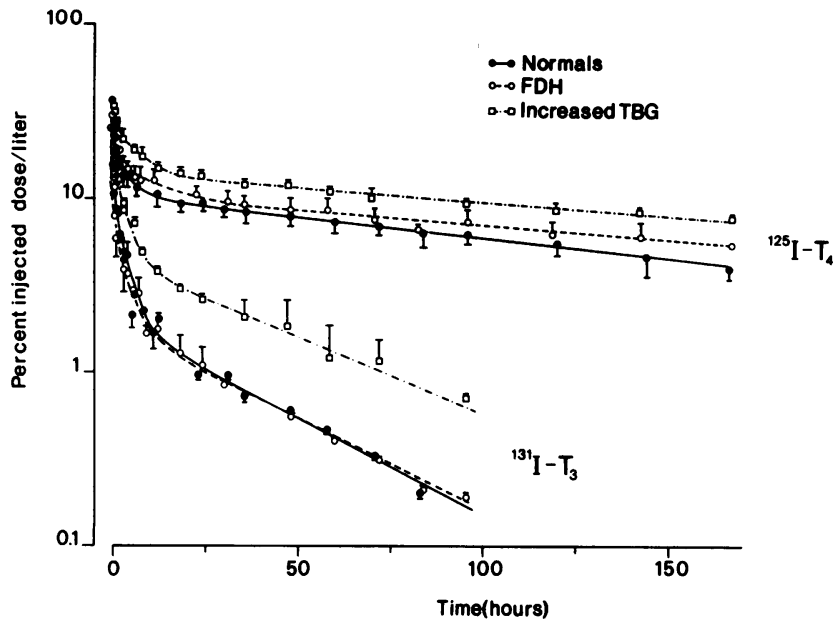

Figure 3. Mean plasma disappearance curves for ${ }^{125} \mathrm{I}-\mathrm{T}_{4}$ and ${ }^{131} \mathrm{I}-\mathrm{T}_{3}$ for the three groups of subjects submitted to the kinetic studies. The curves are represented in a logarithmic scale together with the respective multiexponential fitting functions. The vertical bars represent standard deviation of each average value.

Both $\mathrm{T}_{4}$ IDV (1.73 \pm 0.15 liters $\left./ \mathrm{m}^{2}\right)$ and $\mathrm{T}_{4}$ TDV $(4.98 \pm 1.08$ liters $/ \mathrm{m}^{2}$ ) were similar in FDH and control subjects (Table III). Consequently, total $T_{4}$ extrathyroidal body pool $\left(Q_{t}\right)$ was significantly increased $\left(852 \pm 233 \mu \mathrm{g} / \mathrm{m}^{2}, P<0.001\right)$ in comparison with normal $\left(438 \pm 80 \mu \mathrm{g} / \mathrm{m}^{2}\right)$. $\mathrm{T}_{4} \mathrm{FCR}(10.0 \pm 3.6 \% / \mathrm{d})$ was slightly but significantly reduced $(P<0.05)$ in the FDH subjects as a whole, with subgroup B $(6.9 \pm 2.2 \%, P<0.001)$ contributing most of the change (subgroup $A=12.4 \pm 2.5 \% / d$ ). The $T_{4}$ to $T_{3}$ conversion ratio (CR) was slightly but significantly $(P<0.05)$ reduced $(21.0 \pm 3.8 \%$ vs. $26.1 \pm 5.9 \%)$. This was due to subgroup A $(19.8 \pm 4.1 \% ; P<0.05)$ rather than subgroup B $(23.1 \pm 2.3 \%)$. $\mathrm{T}_{3} \mathrm{MCR}$ was not different from the control subjects. Consequently, the observed increment in total $T_{3} P R(23.7 \%)$ can all be ascribed to the elevation of total serum $T_{3}$ levels. Although still within the normal range, total $T_{3}$ in patients $(141 \pm 18 \mathrm{ng} /$ $100 \mathrm{ml})$ was significantly higher than in controls $(121 \pm 12 \mathrm{ng} /$ $100 \mathrm{ml}, P<0.001$ ), in accord with the findings reported by Ruiz et al. (4). The increase in $T_{3} P R$ was larger (32\%) in subgroup

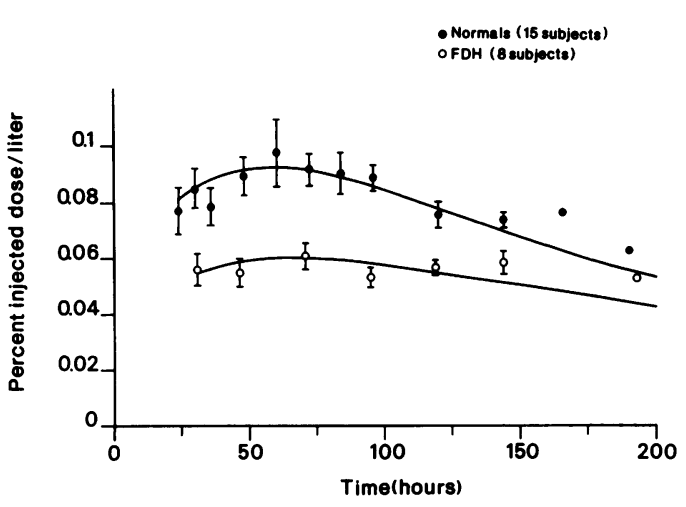

Figure 4. Mean plasma appearance curves of in vivo generated ${ }^{125} \mathrm{I}_{-} \mathrm{T}_{3}$ from ${ }^{125} \mathrm{I}-\mathrm{T}_{4}$ together with the respective fitting functions computed by convolution approach (see data analysis), obtained in normal subjects (upper curve) and in patients with familial dysalbuminemic hyperthyroxinemia (lower curve). The bars represent the standard error of each mean. 


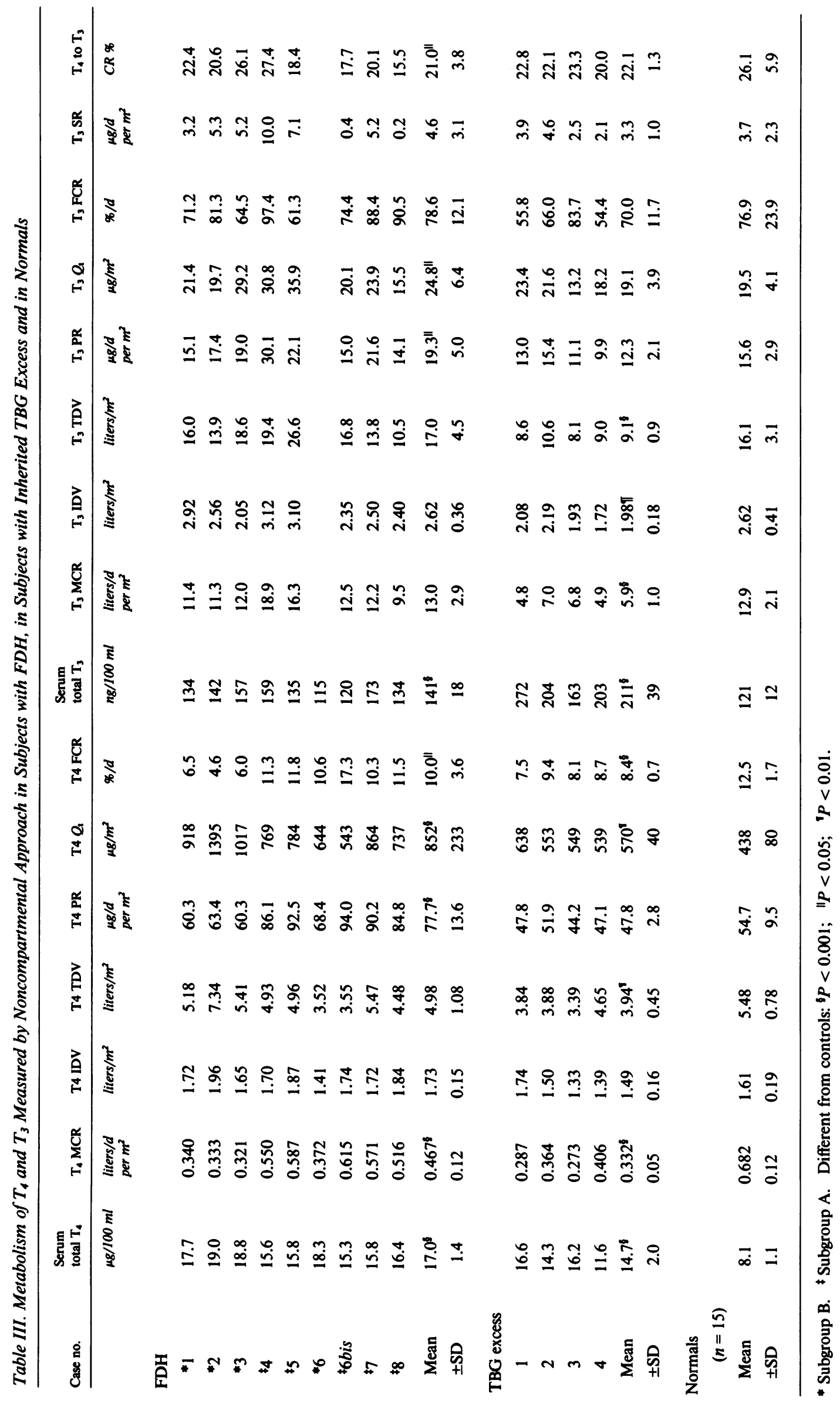




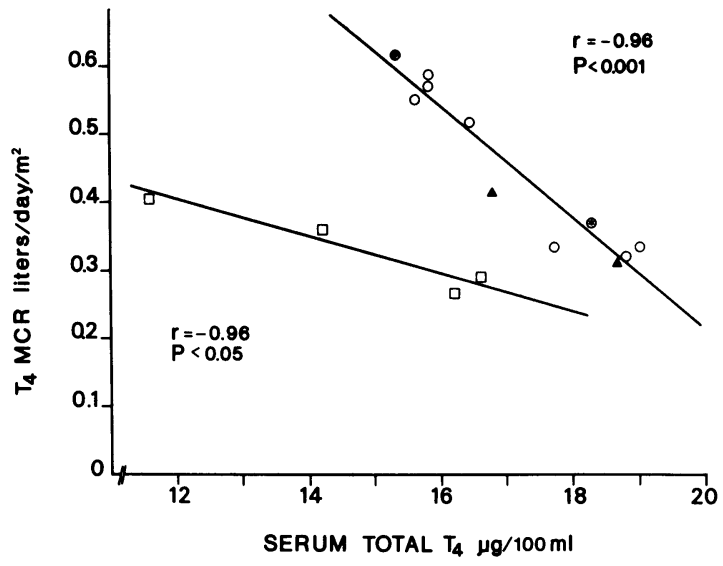

Figure 5. Upper plot: correlation observed between $\mathrm{T}_{4} \mathrm{MCR}$ and total serum $T_{4}$ concentration in patients with familial dysalbuminemic hyperthyroxinemia of the present study (open circles) and in the two patients (solid triangles) studied by Hennemann et al. (1). Symbols with * refers to subject 6 studied at two different times. Affinity constant $\left(K_{\mathrm{a}}\right)$ of abnormal albumin binding sites (aHSA), for $\mathrm{T}_{4}$ : case 6, 4 $\times 10^{6}$ liters $/ \mathrm{mol}$; case 6 bis, $1.8 \times 10^{6}$ liters $/ \mathrm{mol}$. The correlation holds also when our data are normalized by body weight as those reported by Mendel and Cavalieri (10) $(r=0.87 ; P<0.001)$. Lower plot: correlation between $T_{4} M C R$ and total serum $T_{4}$ concentration in subjects with TBG excess (open squares). All values are corrected to body surface.

A than in subgroup $B(10.1 \%)$. The thyroidal $T_{3}$ secretion rate, in percent of total $T_{3} P R(23.8 \pm 11.8 \%)$, as well as the IDV and TDV of $\mathrm{T}_{3}$, all were similar to those of the control subjects. The $\mathrm{T}_{3} Q_{\mathrm{t}}$ increased by $27.2 \%,(P<0.05)$.
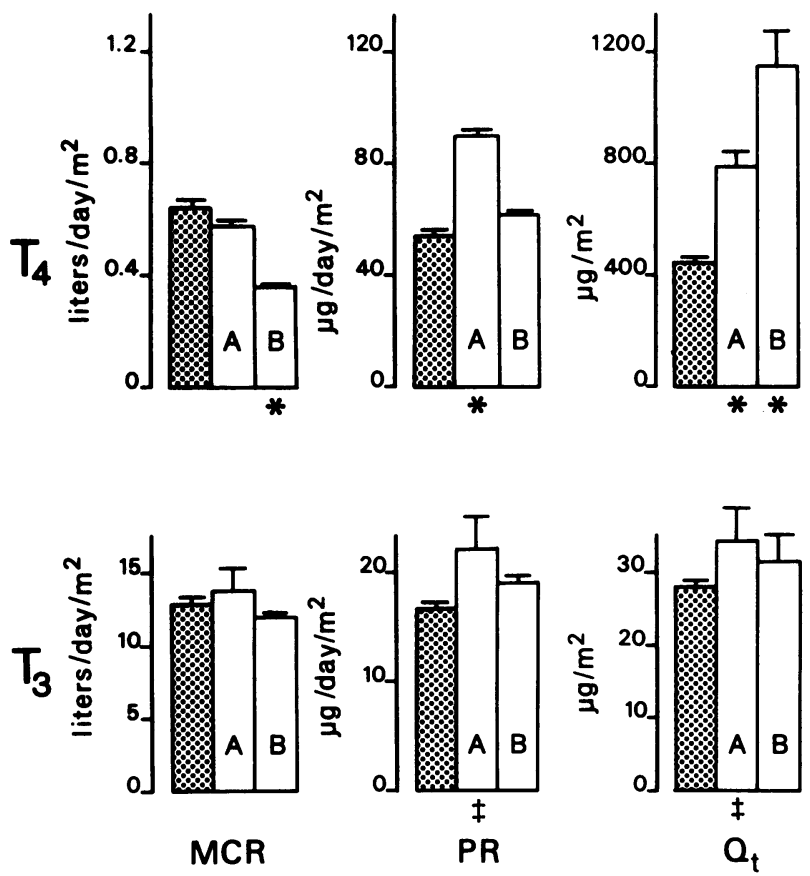

Figure 6. Comparison of $M C R, P R$, and $Q_{t}$ values respectively for $T_{4}$ (upper panel) and $\mathrm{T}_{3}$ (lower panel) for normal subjects and FDH subjects with relatively higher total $\mathrm{T}_{4}$ serum concentration $(18.5 \pm 0.56$ $\mu \mathrm{g} / 100 \mathrm{ml}$, subgroup B) and with relatively lower total $T_{4}$ serum concentration $(15.8 \pm 0.37 \mu \mathrm{g} / 100 \mathrm{ml}$, subgroup A). Values are means; the bars denote standard deviation, * indicates $P<0.001$, $\ddagger$ indicates $P$ $<0.05$ (by unpaired $t$ test).
Subjects with inherited TBG elevation. Both $\mathrm{T}_{4}$ and $\mathrm{T}_{3} \mathrm{MCR}$ were markedly decreased $(P<0.001)$, by $51.3 \%$ and $54.3 \%$ respectively, in comparison with the controls (Table III). $\mathrm{T}_{4}$ and $\mathrm{T}_{3} \mathrm{PR}$ were not different from normal, because the rise in serum hormone concentrations fully compensated the decrease in MCR. A significant inverse correlation was observed between $\mathrm{T}_{4} \mathrm{MCR}$ and total $\mathrm{T}_{4}$ serum concentration $(r=0.96 ; P<0.05$, Fig. 5). It is worth noting that the decrease of $T_{4} M C R$ is associated with a consensual increment of both total serum $T_{4}$ and serum TBG concentrations. $T_{4}$ IDV was slightly lower than normal whereas $\mathrm{T}_{3}$ IDV was significantly reduced, $(P<0.01) . \mathrm{T}_{4}$ and $\mathrm{T}_{3}$ TDV were both significantly decreased (by $28.1 \%, P$ $<0.01$, and $43.5 \%, P<0.001$, respectively). $\mathrm{T}_{4} Q_{\mathrm{t}}$ was increased $(P<0.01)$ because the decrease in TDV did not counterbalance the increase in serum $\mathrm{T}_{4}$ concentration, and $\mathrm{T}_{3} Q_{t}$ was not different in comparison with the control group. $T$ he $T_{4}$ to $T_{3}$ conversion ratio $(22.1 \pm 1.3 \%)$ and thyroidal $T_{3}$ secretion in percent of total $\mathrm{T}_{3}$ PR $(26.8 \%)$ were not significantly different from the normal values. $\mathrm{T}_{4}$ FCR was significantly reduced $(P<0.001)$ whereas $T_{3}$ FCR was only slightly decreased.

Finally, a significant inverse correlation was found to exist between the $\mathrm{T}_{4}$ to $\mathrm{T}_{3}$ conversion ratio and $\mathrm{T}_{4} \mathrm{PR}(r=0.41 ; P$ $<0.05$ ) in the whole of the study subjects. This correlation became stronger when the data from nine hypothyroid patients previously studied by us (34) were included (Fig. 7).

\section{MULTICOMPARTMENTAL ANALYSIS}

Normal subjects. The mean values of production rates, pool masses, and exchange fluxes of the $T_{4}$ and $T_{3}$ systems, computed according to the six-compartment model, are reported in Fig. 8 for the 15 control subjects.

$\mathrm{T}_{4} Q_{\mathrm{t}}\left(448 \pm 82 \mu \mathrm{g} / \mathrm{m}^{2}\right)$ was found to be only minimally (2.2\%) underestimated by the NC approach. The fractions of total $T_{4}$ $Q_{t}$ in the initial distribution (or plasma) pool and in the fast and slowly exchanging tissue pools, were $28.8 \%, 28.8 \%$, and $42.4 \%$, respectively; these figures are similar to those reported by $\mathrm{Di}$ Stefano et al. in rats (28). $T_{3} P R$ resulted to be $16.9 \pm 3.3 \mu \mathrm{g} / \mathrm{d}$ per $\mathrm{m}^{2}$, and was $7.7 \%$ underestimated by the NC approach; the $\mathrm{T}_{4} \mathrm{PR}$ metabolized by routes different from $\mathrm{T}_{3}$ generation was $38.9 \pm 9.5 \mu \mathrm{g} / \mathrm{d}$ per $\mathrm{m}^{2} . \mathrm{T}_{4}$ to $\mathrm{T}_{3} \mathrm{CR}$ was $29.2 \pm 6.5 \%$ and, because

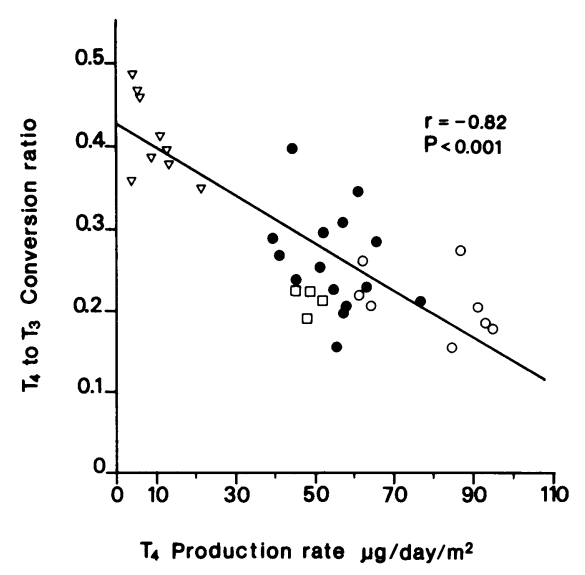

Figure 7. Inverse correlation observed in the whole series of subjects of the present study and in nine hypothyroid patients, previously reported (34) between the conversion ratio values and $T_{4}$ daily production rates. (Solid circles) Normal subjects, (open circles) FDH subjects, (open squares) subjects with TBG excess, (inverted triangles) hypothyroid subjects. 


\section{Normals (15)}

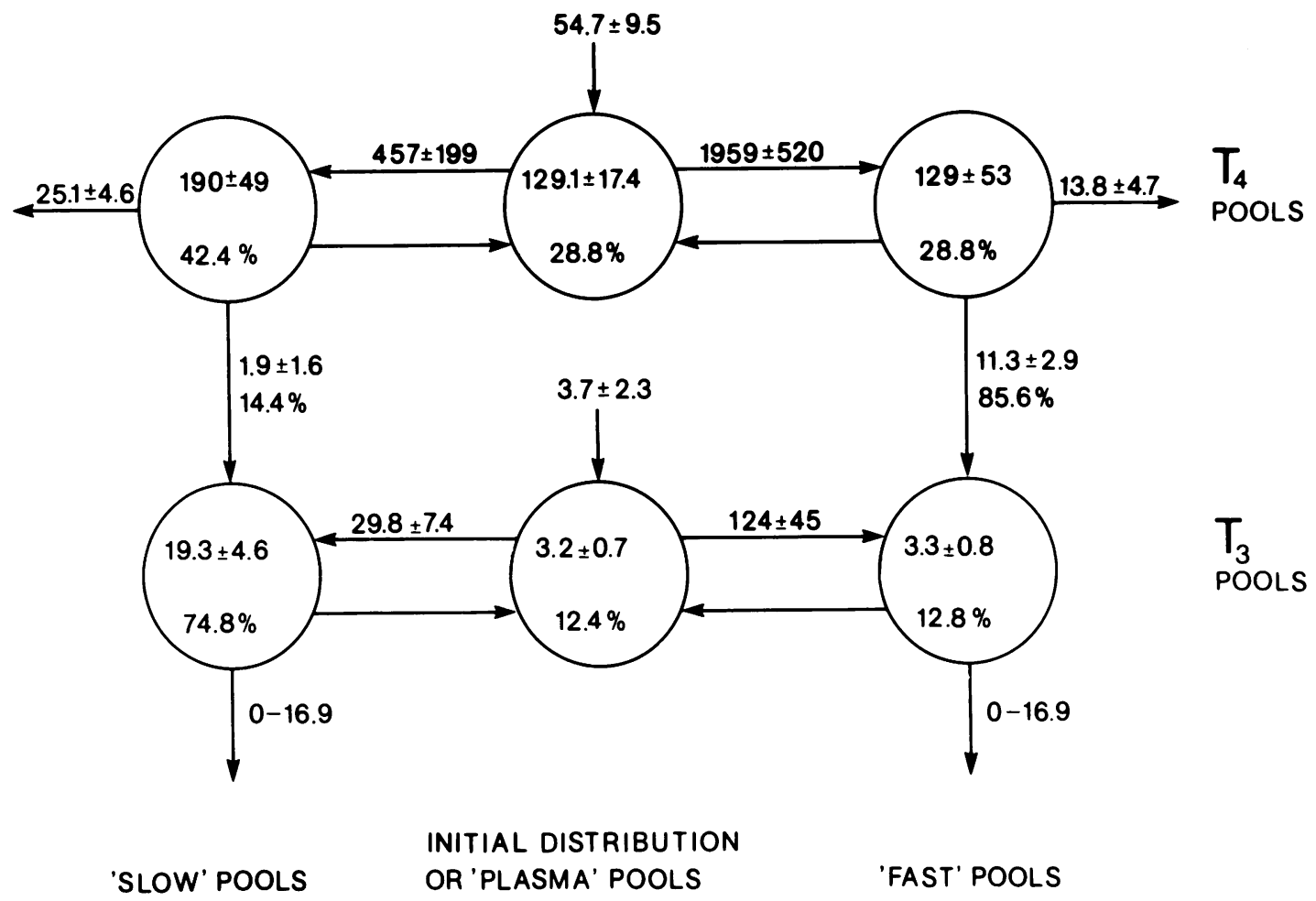

Figure 8. Mean results from multicompartmental analysis of $\mathrm{T}_{4}$ and $T_{3}$ kinetics in normals. The figure shows mean values ( \pm standard deviation) of masses (figures within circles in $\mu \mathrm{g} / \mathrm{m}^{2}$ ) of initial distribution compartment and of the fast and the slowly exchanging compartments, both for $T_{4}$ and $T_{3}$. The same values are also indicated as percentage of the respective total (extrathyroidal) body pools. For $T_{4}$ system, we also report (on the respective arrows in $\mu \mathrm{g} / \mathrm{d} \mathrm{per} \mathrm{m}^{2}$ of $\mathrm{T}_{4}$ ), the production rate of $T_{4}$, the exchange rates between central and peripheral compartments and the degradation rate of $T_{4}$ associated to pathways different from conversion into $T_{3}$. For $T_{3}$ system we report (on the respective arrows in $\mu \mathrm{g} / \mathrm{d}_{\text {per }} \mathrm{m}^{2}$ of $\mathrm{T}_{3}$ ), the thyroidal secretion, the peripheral production rates from $T_{4}$ conversion both in the fast and in the slow peripheral compartments, the exchange rates between central and peripheral compartments and the disposal rate. The disposal rate is reported as an interval on both peripheral pools, in that the analysis does not allow identifying in which of the peripheral

it refers to the peripheral $\mathrm{T}_{3}$ production only, it was more underestimated $(10.6 \%)$ by $\mathrm{NC}$ analysis. Total $\mathrm{T}_{3} Q_{t}$ was $25.8 \pm 5.0$ $\mu \mathrm{g} / \mathrm{m}^{2}$; NC analysis underestimated this parameter by $24.4 \%$. Percent distribution in the initial, fast, and slow pools was $12.4 \%$, $12.8 \%$, and $74.8 \%$, similar to those reported by Di Stefano et al. in rats (29) and by Hershman et al. in humans (30). It must be noted that $78 \%$ of $\mathrm{T}_{3}$ PR emanates from peripheral conversion of $\mathrm{T}_{4}$, of which $86 \%$ and $14 \%$ originate from the fast and slowly exchanging tissue pools, respectively. This is at variance with the peripheral $T_{3}$ production in the rat, where the major fraction of the hormone is generated from $\mathrm{T}_{4}$ in the slowly exchanging pool (29).

FDH subjects. $\mathrm{T}_{4} Q_{\mathrm{t}}$ was $917 \pm 242 \mu \mathrm{g} / \mathrm{m}^{2}$. The underestimation produced by NC analysis was $7 \%$. The proportion of total $\mathrm{T}_{4} Q_{\mathrm{t}}$ in the plasma pool, fast and slowly exchanging tissue pools were $32.4 \%, 21.8 \%, 45.8 \%$, respectively. Total $\mathrm{T}_{3} Q_{\mathrm{t}}$ was $33.1 \pm 9.3 \mu \mathrm{g} / \mathrm{m}^{2}$, higher than the value obtained by $\mathrm{NC}$ analysis

$T_{3}$ pools the degradation takes place. The following additional kinetic parameters, useful for comparing MC with NC analysis, are easily computed using the data in the figure and the mean plasma concentrations of the hormones (see Table I), according to the following formulas:

$\mathrm{T}_{4} \mathrm{TDV}=\mathrm{T}_{4} Q_{\mathrm{t}}\left(\mu \mathrm{g} / \mathrm{m}^{2}\right) /$ serum $\mathrm{T}_{4}$ level $(\mu \mathrm{g} /$ liter $)$

$$
=(129+129+190) / 81=5.53 \text { liters } / \mathrm{m}^{2} ;
$$

$\mathrm{T}_{3} \mathrm{TDV}=\mathrm{T}_{3} Q_{\mathrm{t}}\left(\mu \mathrm{g} / \mathrm{m}^{2}\right) /$ serum $\mathrm{T}_{3}$ level $(\mu \mathrm{g} /$ liter $)$

$$
=(3.2+3.3+19.3) / 1.21=21.3 \text { liters } / \mathrm{m}^{2} ;
$$

$T_{4}$ to $T_{3} C R(\%)=$ peripheral $T_{3}$ production

$$
\times\left(\mathrm{mol} \mathrm{wt} \mathrm{T}_{4} / \mathrm{mol} \mathrm{wt}_{3}\right) / \mathrm{T}_{4} \mathrm{PR}=13.2 \times 1.2 / 54.7=29.0 \% \text {. }
$$

(by 33.5\%). The fractions of total $\mathrm{T}_{3} Q_{\mathrm{t}}$ in the plasma, fast and slowly exchanging tissue pools $(11.5 \%, 12.1 \%$, and $76.4 \%)$ were very similar to the corresponding figures found in normals. $T_{3}$ PR was $21.2 \pm 5.1 \mu \mathrm{g} / \mathrm{d} \mathrm{per} \mathrm{m}^{2}$, significantly greater $(P<0.05)$ than control values $\left(16.9 \pm 3.3 \mu \mathrm{g} / \mathrm{d} \mathrm{per}^{2}\right.$ ) (Fig. 9). This value was underestimated by $\mathrm{NC}$ analysis by $9 \%$. $\mathrm{T}_{4}$ to $\mathrm{T}_{3} \mathrm{CR}$ was $25.6 \pm 2.9 \%$, slightly less than normal $(29.2 \pm 6.5 \%)$; this figure was underestimated by NC analysis by $18 \%$. The mean fraction of $T_{4} P R$ metabolized by other routes than $T_{3}$ generation was $74 \%$, practically superimposable to the values found in the controls (71\%).

In FDH subjects, $78.3 \%$ of the $T_{3}$ PR emanates from extrathyroidal conversion from $T_{4}$; this figure is identical to the corresponding normal value $(78.1 \%)$. However, of this amount $57.8 \%$ and $42.2 \%$ come, respectively, from fast and slowly exchanging tissue pools in FDH in comparison with the corresponding values of $85.6 \%$ and $14.4 \%$ in the controls. The shift 


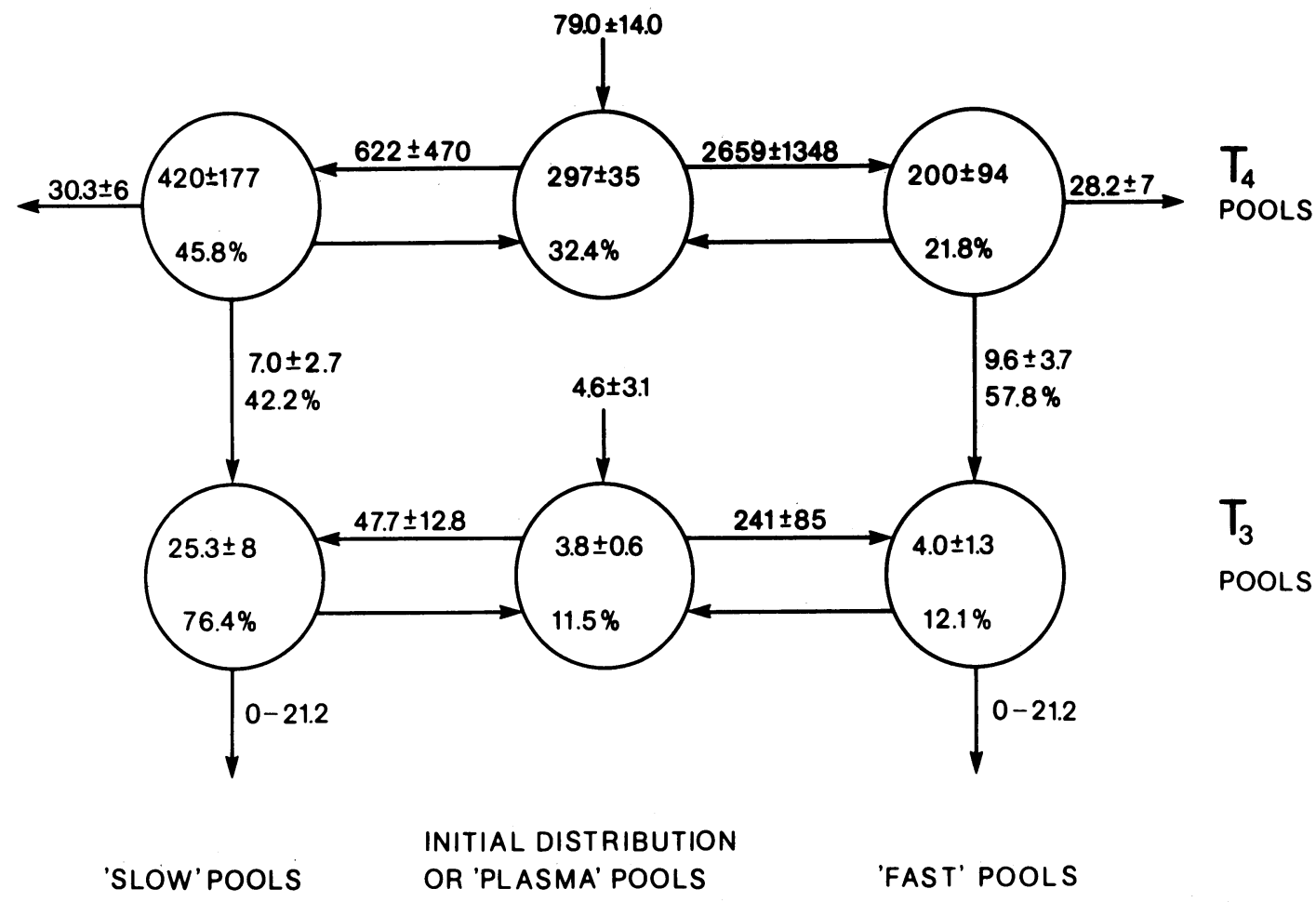

Figure 9. Mean results from MC analysis of $T_{4}$ and $T_{3}$ kinetics in FDH subjects; see legend of Fig. 8 for explanations. Additional parameters are easily computed using the formulas reported in the legend of Fig. 8: $T_{4} T D V=5.39$ liters $/ \mathrm{m}^{2}, T_{3} T D V=23.5$ liters $/ \mathrm{m}^{2} ; T_{4}$ to $T_{3} C R=25.2 \%$.

of peripheral $\mathrm{T}_{3}$ production toward the slow compartment $(P$ $<0.001)$ is reflected by the shape of the plasma appearance curve of neogenerated ${ }^{125} \mathrm{I}_{-} \mathrm{T}_{3}$ (Fig. 4), which appears to lag behind the normal curve. The overall $T_{4}$ transfer rate (TR) from plasma, although significantly increased $(P<0.05)$ in absolute terms $(3,281 \pm 1,267$ in respect to normal value of $2,416 \pm 496 \mu \mathrm{g} / \mathrm{d}$ per $\left.\mathrm{m}^{2}\right)$ is significantly reduced $(P<0.001)$ when represented as percent of the plasma pool $(1,108$ vs. $1,871 \% / d)$.

High-TBG subjects. $\mathrm{T}_{4}$ and $\mathrm{T}_{3} Q_{\mathrm{t}}$ were $596 \pm 37$ and $25.0 \pm 6.3$ $\mu \mathrm{g} / \mathrm{m}^{2}$, respectively (Fig. 10). These values were higher than those obtained by $\mathrm{NC}$ analysis (by $4.6 \%$ and $31 \%$ ). For both $\mathrm{T}_{4}$ and $\mathrm{T}_{3}$ there was an increase in the amount present in the plasma pools, either in absolute terms $\left(220 \pm 46\right.$ and $\left.4.2 \pm 1 \mu \mathrm{g} / \mathrm{m}^{2}\right)$ and in percentage (respectively, $36.9 \%$ and $16.8 \%$ ) in comparison with the normal situation. Overall $T_{4}$ TR from plasma $\left(1,937 \pm 379 \mu \mathrm{g} / \mathrm{d}\right.$ per $\left.\mathrm{m}^{2}\right)$, although not different from normal in absolute terms, was significantly reduced $(P<0.001)$ in percent terms ( 880 vs. $1,871 \% / d)$. The mean fraction of $T_{4} P R$ metabolized by other pathways than $\mathrm{T}_{3}$ generation was $75.9 \%$, similar to the value found in the controls and in FDH subjects. Respectively, $74 \%$ and $26 \%$ of $\mathrm{T}_{3}$ generated in peripheral tissues from $\mathrm{T}_{4}$ derived from fast and slowly exchanging tissue pools.

\section{Discussion}

The present study was undertaken to investigate the specific role of serum carrier proteins of two different thyroid hormones, characterized respectively by the highest affinity (TBG) and by the highest capacity (albumin), in the availability of $T_{4}$ and $T_{3}$ to peripheral tissues. In vivo $T_{4}$ and $T_{3}$ kinetic studies were carried out in normal subjects and in individuals with congenital thyroid hormone carrier protein defects, characterized by excessive total serum $T_{4}$ concentrations and by normal free $T_{4}$ levels. In high TBG and FDH, euthyroid hyperthyroxinemia is due to an increase in TBG serum concentration in the former, and to the presence of abnormal albumin binding sites in the latter. The methods we used allow simultaneous in vivo assessment of $T_{4}$ and $T_{3}$ kinetics. In particular, the overall $T_{4}$ into $T_{3}$ conversion ratio, peripheral $T_{3}$ production, and consequently, thyroidal $\mathrm{T}_{3}$ secretion rate can be directly measured. In addition, the amount of $T_{4}$ metabolized by other routes than $T_{3}$ generation (deiodination to $\mathrm{rT}_{3}$, conjugation, decarboxylation, deamination, urinary and fecal excretion) can be estimated. The multicompartmental approach provides the partition of $T_{4}$ and $T_{3}$ extrathyroidal body pools among the plasma, slowly and fast exchanging tissue pools, and the relative contribution of slowly and fast exchanging compartments to peripheral $T_{3}$ neogenesis.

Because MCR is defined as the ratio between disposal rate and plasma concentration, it can be considered as an index of the availability of the hormone for disposal and, in the case of $T_{4}$, for its conversion into $T_{3}$. It was thus found that the availability of $T_{4}$ is markedly reduced in subjects with congenital elevation of TBG; their higher $T_{4}$ levels ensure a normal disposal rate of $T_{4}$. In that the conversion ratio of $T_{4}$ into $T_{3}$ is unchanged, peripheral $T_{3}$ production remains in the normal range. The reduced $T_{4}$ availability in this condition is confirmed by the significant increase $(P<0.001)$ of the initial distribution (or plasma) pool (36.9\% of the total pool vs. $28.8 \%$ of the controls) and also by the changes in $T_{4}$ TR from plasma and in $T_{4} F C R$, which are reduced by $53 \%$ and $32.8 \%$, respectively. A close reduction of $\mathrm{T}_{4}$ FCR in congenital TBG elevation has been reported also by Nicoloff et al. (35). 


\section{Increased TBG (4)}
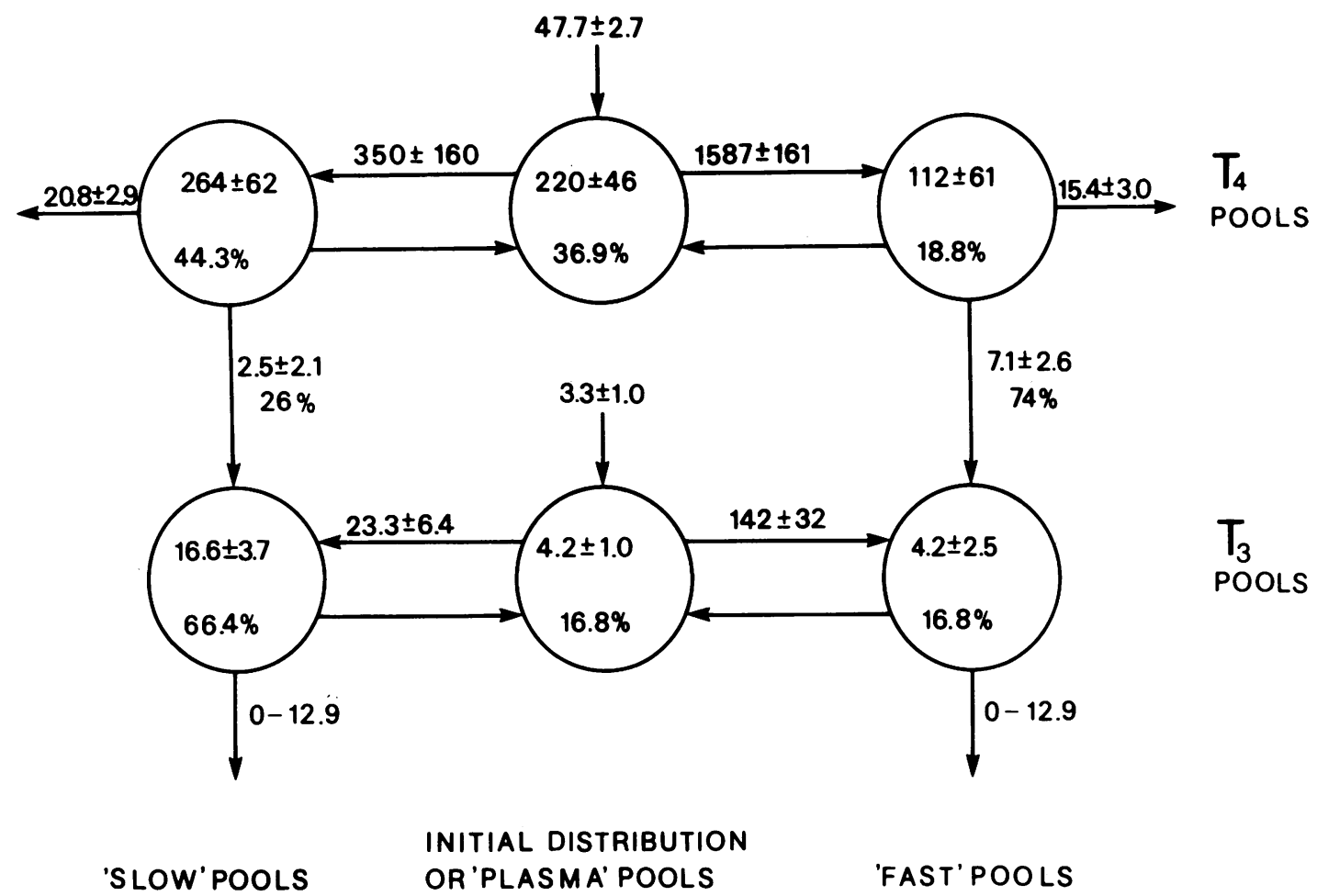

\section{'FAST'POOLS}

Figure 10. Mean results from MC analysis of $T_{4}$ and $T_{3}$ kinetics in subjects with congenital TBG excess; see legend of Fig. 8 for explanations. Additional kinetic parameters are easily computed using the formulas reported in the legend of Fig. 8: $T_{4} T D V=4.05$ liters $/ \mathrm{m}^{2}, T_{3} T D V=11.8$ liters $/ \mathrm{m}^{2}, \mathrm{~T}_{4}$ to $\mathrm{T}_{3} \mathrm{CR}=24.2 \%$.

The reduction of $\mathrm{T}_{4} \mathrm{MCR}$ in FDH subjects was less marked than that found in the increased TBG state, indicating that the $\mathrm{T}_{4}$ carried by abnormal albumin is more available to peripheral tissues than the $T_{4}$ carried by TBG. Accordingly, both $T_{4} T R$ and $\mathrm{T}_{4} \mathrm{FCR}$ were diminished less in FDH (40\% and $20 \%$, respectively) than in TBG subjects ( $53 \%$ and $32.8 \%$, respectively) in comparison with the control group. Furthermore, the higher $\mathrm{T}_{4}$ availability to peripheral tissues in FDH subjects is confirmed by their normal TDV values whereas in high-TBG subjects TDV was significantly decreased and actually superimposable on the distribution volume of TBG itself (36). TDV values in our FDH cases were similar to those reported by Hennemann et al. (1) and Mendel and Cavalieri (10), who, however, calculated TDV values in the control subjects higher than those obtained by other authors $(35,37,38)$ and by us.

Our findings are apparently in contrast with in vivo observations of Mendel and Cavalieri (10) and Hennemann et al. (1) in humans and of Cefalu et al. (11) in rat liver. These authors argue against a special role of albumin in FDH in $\mathrm{T}_{4}$ transport. Concerning the experimental study, the question arises whether the rat liver can serve as a valid model for studying overall $T_{4}$ availability to peripheral tissues in humans. For the studies in human beings, this discrepancy could stem from differences in the methods used for the in vivo kinetic evaluation or from differences in the subjects studied. The former possibility is unlikely because the results obtained in the present study in the subjects with increased TBG and in the control group are in agreement with those reported previously $(35,37,38)$.

The highly significant, inverse correlation $(r=0.96 ; P$
$<0.001$ ) observed between $\mathrm{T}_{4} \mathrm{MCR}$ and the serum $\mathrm{T}_{4}$ concentration suggests the existence in FDH of a variability in the affinity and/or capacity of the abnormal albumin-binding sites. The correlation holds also when the data of Henneman et al. (1) $(r=-0.96 ; P<0.001)$ and those of Mendel and Cavalieri (10) $(r=-0.87 ; P<0.001)$, who normalized the data by body surface area and body weight respectively, are alternatively included (Fig. 5). It is worth noting that the affinity of the abnormal albumin-binding site for $T_{4}$ can vary, as shown by our measurements of the $K_{\mathrm{a}}$ of abnormal albumin and $\mathrm{T}_{4} \mathrm{MCR}$ in the same FDH subject (case 6 and 6 bis) at different times; the observed reduction of $K_{\mathrm{a}}$ and of serum $\mathrm{T}_{4}$ in this subject was associated with a relatively larger increase of $T_{4} M C R$ and, consequently, of $\mathrm{T}_{4} \mathrm{PR}$ (see Table III and Fig. 5). Although the precise mechanism responsible for this phenomenon is unknown, the explanation could include a ligand-carrier protein interaction involving a conformational change in some of the albuminbinding sites $(39,40)$. The significant increase in $T_{4} P R$ in our FDH subjects can be accounted for by a relatively lower reduction of $\mathrm{T}_{4} \mathrm{MCR}$ in this condition in comparison to that observed in congenital elevation of TBG. In fact, it is remarkable that for identical or similar values of serum $\mathrm{T}_{4}$ concentration, the subjects with high TBG showed much lower $T_{4}$ MCR values than the FDH subjects (Fig. 5; Table III). Therefore, the disagreement of the $T_{4} P R$ in the present series with those previously reported $(1,10)$, can be explained by differences among the subjects studied. In fact, in the subgroup of subjects with relatively higher total serum $\mathrm{T}_{4}$ concentration $(18.5 \pm 0.76 \mu \mathrm{g} / 100 \mathrm{ml}$, subgroup $B$ ), the increment in $T_{4} P R$ over the control value was only 
$15.3 \%$ (not significant), and this figure is similar to the data reported by Hennemann et al. (1) (total $T_{4} 17.7 \pm 0.9 \mu \mathrm{g} / 100$ $\mathrm{ml}, \mathrm{T}_{4} \mathrm{PR}$ increase $20 \%$ ). In contrast, an increased $\mathrm{T}_{4}$ availability in the FDH subjects with relatively lower total serum $T_{4}$ concentrations $\left(T_{4} 15.8 \pm 0.37 \mu \mathrm{g} / 100 \mathrm{ml}\right.$, subgroup $\left.A\right)$ is supported by the finding of a $\mathrm{T}_{4} \mathrm{MCR}$ value not different from the control value, and of a significant increase in the $T_{4}$ production rate (see Fig. 6).

The increase in peripheral $T_{3} P R$ in the face of an unchanged $T_{3}$ thyroidal secretion, and of a small but significant reduction of $T_{4}$ to $T_{3}$ conversion confirms the increased $T_{4}$ bioavailability. The observed decrease in the overall $T_{4}$ to $T_{3}$ conversion ratio and the highly significant increase in the amount of $\mathrm{T}_{3}$ produced in slowly exchanging tissue pools suggest the presence of FDH of a peripheral autoregulatory mechanism attenuating the effect of increased $\mathrm{T}_{4}$ availability. The significant increment in total serum $T_{3}$ can be ascribed to augmented peripheral $T_{3} P R$, rather than to increased $T_{3}$ affinity of the abnormal albumin-binding sites, as suggested by Ruiz et al. (4). Our hypothesis is consistent with the finding of normal values of $\mathrm{T}_{3} \mathrm{MCR}$ and FCR in FDH subjects, as opposed to the reduction of these parameters in subjects with congenital elevation of TBG (Table III).

The consensual change of total serum $\mathrm{T}_{4}$ concentration and overall $\mathrm{T}_{4}$ to $\mathrm{T}_{3}$ conversion $(n=7, r=0.70)$ in FDH subjects is at variance with the inverse correlation between these parameters reported by other authors and by us in subjects without alteration of thyroid hormones serum carrier proteins $(12,41$, 42). However, the overall $T_{4}$ to $T_{3}$ conversion ratio appears to bear a closer relationship to $T_{4} P R$ than to serum $T_{4}$ concentration. This is supported by the tight inverse correlation between $T_{4}$ to $T_{3}$ conversion and $T_{4} P R$ which emerged when all the studies (normals, FDH, and high-TBG subjects, hypothyroid patients) were pooled (Fig. 7). This finding may reflect the main peripheral tissue autoregulatory mechanism for maintaining $T_{3}$ production rate and circulating $T_{3}$ levels, because $T_{4}$ to $T_{3}$ conversion only occurs within the cells, where $T_{4}$ concentration may be different from that observed in the serum. In FDH the large increase in the amount of $\mathrm{T}_{4}$ carried by abnormal albumin molecules, and the parallel decrement in the $T_{4}$ carried by TBG (Fig. 2), can be viewed as facilitated serum hormone transport into the peripheral tissues. With regard to this, it should be borne in mind that the measured affinity constant for $T_{4}$ of the $a b-$ normal albumin-binding sites was still $\sim 1,000$-fold lower than the affinity constant of TBG binding sites (Table II).

The increased bioavailability of $\mathrm{T}_{4}$ in FDH subjects, contrasted with the situation in congenital elevation of TBG, and particularly their increased $T_{4}$ disposal rate suggests an independent, special role of normal albumin for $T_{4}$ delivery to the peripheral tissues. This hypothesis is consistent with the finding of a dramatic increase in $T_{4}$ MCR and FCR in normal or hypothyroid patients with congenital absence of TBG, where $T_{4}$ is carried exclusively by albumin and thyroxine-binding prealbumin (43-46). The lack of correlation between the $T_{4}$ disposal rate and its free serum concentration in subjects with inherited absence of TBG, in the face of a normal daily $T_{4} P R$ and reduced circulating free $T_{4}$ levels (47), can again be explained by the higher availability for entry into the peripheral tissues of $T_{4}$ carried by normal albumin as compared with $T_{4}$ carried by TBG. This is in contrast to the results reported by Cefalu et al. (11), who observed that FDH albumin, like TBG, delays the uptake of $\mathrm{T}_{4}$ by rat liver cells. However, they found a significantly greater hepatic $\mathrm{T}_{4}$ extraction from FDH serum in comparison with nor- mal, but they did not find any difference in the concentration of bioavailable $T_{4}$ between FDH and control serum. These data are in agreement with the findings of in vivo kinetic studies in humans of Mendel and Cavalieri (10), who showed that the absolute rate of $\mathrm{T}_{4}$ flux into the rapidly exchangeable cellular compartment (liver) is normal in FDH. Both authors concluded that FDH albumin, like TBG, sequesters $T_{4}$ in the plasma compartment.

In conclusion, the present study indicates that the $T_{4}$ bound to FDH albumin-binding sites, although less available than $T_{4}$ bound to normal albumin, still is more available to peripheral tissues than $T_{4}$ carried by TBG. Our data are in agreement with those of Premachanidra et al. (48), who found enhanced rate of red cells and lymphocytes uptake of $T_{4}$ from sera of FDH subjects.

In species such as man, the evolutionary development of a specific thyroxine-binding protein (TBG) is associated with a large increase in extracellular thyroid hormone reservoir, directly regulating the circulating levels of $T_{4}$ and $T_{3}$. On the contrary, the primary role of albumin-mediated hormone transport to the tissues could be based on a mechanism involving ligand-serum carrier protein interaction. In a previous paper, we provided evidence that the hormone-binding protein interaction proceeds through the fast formation of a labile hormone-protein complex that successively rearranges to give the final complex and that the intermediate hormone-protein complex dissociates faster than the final complex. Moreover, the fraction of the $T_{4}$ bound in the labile intermediate complex is $\sim 30 \%$ of the albuminbound $\mathrm{T}_{4}$ but only $0.4 \%$ of the TBG-bound $\mathrm{T}_{4}$. This implies that a definite fraction of bound hormone can be released from the carried protein in very short times $(39,49,50)$.

The consequence of a very high dissociation rate of a loosely albumin bound hormone is that, if the free hormone is lost from the bloodstream across the capillary walls, a quasi-equilibrium can be restored almost instantaneously through prompt dissociation of the bound hormone in the intermediate complex. In this way, not only is the actual free hormone made available to peripheral tissues but also a substantial part of the albuminbound hormone can be used even in tissues characterized by a short capillary transit time.

\section{Acknowledgments}

The authors wish to thank Dr. Eleuterio Ferrannini for the stimulating criticism and careful review of this paper. The authors wish also to thank Miss Daniela Banti for her expert and patient typing of the manuscript.

\section{References}

1. Hennemann, G., R. Docter, E. P. Krenning, G. Bos, M. Otten, and T. J. Visser. 1979. Raised total thyroxine and free thyroxine index but normal free thyroxine. Lancet. i:639-642.

2. Lee, W. N. P., M. P. Golden, A. J. Van Herle, B. M. Lippe, and S. A. Kaplan. 1979. Inherited abnormal thyroid hormone-binding protein causing selective increase of total serum thyroxine. J. Clin. Endocrinol. Metab. 49:292-299.

3. Stockigt, J. R., D. J. Topliss, J. W. Barlow, E. L. White, D. M. Hurley, and P. Taft. 1981. Familial euthyroid thyroxine excess: an appropriate resonse to abnormal thyroxine binding associated with albumin. J. Clin. Endocrinol. Metab. 53:353-359.

4. Ruiz, M., R. Rajatanavin, R. A. Young, C. Taylor, R. Brown, L. E. Braverman, and S. H. Ingbar. 1982. Familial dysalbuminemic hyperthyroxinemia. N. Engl. J. Med. 306:635-639. 
5. Beierwaltes, W. H., and J. Robbins. 1959. Familial increase in the thyroxine-binding sites in serum alpha globulin. J. Clin. Invest. 38:16831688.

6. Burr, W. A., D. Ramsdem, and R. Hoffenberg. 1980. Hereditary abnormalities of thyroxine-binding globulin concentration. $Q$. J. Med. 49:295-313.

7. Borst, G. C., C. Eil, and K. D. Burman. 1983. Euthyroid hyperthyroxinemia. Ann. Intern. Med. 98:366-378.

8. Oppenheimer, J. H., G. Bernstein, and J. Hasen. 1967. Estimation of rapidly exchangeable cellular thyroxine from the plasma disappearance curves of simultaneously administered thyroxine- ${ }^{131} \mathrm{I}$ and albumin- ${ }^{125} \mathrm{I}$. J. Clin. Invest. 46:762-777.

9. Pardridge, W. M., and L. J. Mietus. 1980. Influx of thyroid hormones into rat liver in vivo: differential availability of thyroxine and triiodothyronine bound by plasma proteins. J. Clin. Invest. 66:367-374.

10. Mendel, C. M., and R. R. Cavalieri. 1984. Thyroxine distribution and metabolism in familial dysalbuminemic hyperthyroxinemia. J. Clin. Endocrinol. Metab. 59:499-504.

11. Cefalu, W. T., W. M. Pardridge, and B. N. Premachandra. 1985. Hepatic bioavailability of thyroxine and testosterone in familial dysalbuminemic hyperthyroxinemia. J. Clin. Endocrinol. Metab. 61:783-786.

12. Bianchi, R., G. Mariani, N. Molea, F. Vitek, F. Cazzuola, A. Carpi, and M. G. Toni. 1983. Peripheral metabolism of thyroid hormones in man. I. Direct measurement of the conversion rate of thyroxine to 3,5,3'-triiodothyronine $\left(T_{3}\right)$ and determination of the peripheral and thyroidal production of $\mathrm{T}_{3}$. J. Clin. Endocrinol. Metab. 56:1152-1163.

13. Sterling, K., and M. A. Brenner. 1966. Free thyroxine in human serum: simplified measurement with the aid of magnesium chloride precipitation. J. Clin. Invest. 45:153-163.

14. Clerico, A., G. C. Zucchelli, L. Fusani, D. Giannessi, G. Mariani, and R. Bianchi. 1976. A simplified method for measuring free triiodothyronine in serum by combined equilibrium dialysis and gel Sephadex extraction. J. Nucl. Biol. Med. 20:176-178.

15. Davis, P. J., and R. I. Gregerman. 1970. Separation of thyroxine $\left(\mathrm{T}_{4}\right)$-binding proteins of human serum in polyacrylamide gel at $\mathrm{pH} 7.4$. I. Effect of $\mathrm{pH}$ on distribution of tracer quantities of $\mathrm{T}_{4}$. J. Clin. Endocrinol. Metab. 30:237-245.

16. Bianchi, R., N. Molea, F. Cazzuola, L. Fusani, and G. Mariani. 1981. Preparation of radioiodothyronines for turnover studies in man. J. Nucl. Med. Allied Sci. 25:133-139.

17. Dunn, J. F., B. C. Nisula, and D. Rodbard. 1981. Transport of steroid hormones: binding of 21 endogenous steroids to both testosteronebinding globulin and corticosteroid-binding globulin in human plasma. J. Clin. Endocrinol. Metab. 53:58-68.

18. Gartner, R., R. Henze, K. Horn, C. R. Pickardt, and P. C. Scriba. 1981. Thyroxine-binding globulin: investigation of microheterogeneity. J. Clin. Endocrinol. Metab. 52:657-664.

19. Scatchard, G. 1949. The attractions of proteins for small molecules and ions. Ann. N.Y. Acad. Sci. 51:660-672.

20. Travis, J., J. Bowen, D. Tewksbury, D. Johnson, and R. Pannel. 1976. Isolation of albumin from whole plasma and fractionation of albumin-depleted plasma. Biochem. J. 157:301-306.

21. Sutherland, R. L., and M. W. Simpson-Morgan. 1975. The thyroxine-binding properties of serum proteins: a competitive binding technique employing Sephadex G-25. J. Endocrinol. 65:319-326.

22. Tait, J. F. 1963. Review: the use of isotopic steroids for the measurements of production rates in vivo. J. Clin. Endocrinol. Metab. 23: 1285-1297.

23. Gurpide, E., and J. Mann. 1970. Interpretation of isotopic data obtained from blood-borne compounds. J. Clin. Endocrinol. Metab. 30: 707-718.

24. Bianchi, R., G. C. Zucchelli, D. Giannessi, A. Pilo, G. Mariani, A. Carpi, and M. G. Toni. 1977. Evaluation of triiodothyronine $\left(T_{3}\right)$ kinetics in normal subjects, in hypothyroid and hyperthyroid patients using specific antiserum for the determination of labeled $\mathrm{T}_{3}$ in plasma. J. Clin. Endocrinol. Metab. 46:203-214.

25. Bianchi, R., A. Pilo, G. Mariani, N. Molea, F. Cazzuola, M. Ferdeghini, and P. Bertelli. 1984. Comparison of plasma and urinary methods for the direct measurement of the thyroxine to 3,5,3'-triiodothyronine conversion rate in man. J. Clin. Endocrinol. Metab. 58:9931002.

26. Pilo, A., R. Bianchi, and N. Molea. 1984. Kinetic analysis of double tracer studies: measurement of the triiodothyronine $\left(T_{3}\right)$ production rate from extra-thyroidal thyroxine $\left(\mathrm{T}_{4}\right)$ conversion in man. In Computers in Endocrinology. D. Rodbard and G. Forti, editors. Raven Press, New York. 245-257.

27. Di Stefano, J. J., III. 1982. Noncompartmental vs. compartmental analysis: some bases for choice. Am. J. Physiol. 243:R1-R6.

28. Di Stefano, J. J., III, T. K. Malone, and M. Jang. 1982. Comprehensive kinetics of thyroxine $\left(\mathrm{T}_{4}\right)$ distribution and metabolism in blood and tissue pools of the rat from only six blood samples: dominance of large, slowly exchanging tissue pools. Endocrinology. 111:108-117.

29. Di Stefano, J. J., III, M. Jang, T. K. Malone, and M. Broutman. 1982. Comprehensive kinetics of triiodothyronine production, distribution, and metabolism in blood and tissue pools of the rat using optimized blood-sampling protocols. Endocrinology. 110:198-213.

30. Hershman, J. M., K. Nademanee, M. Sugawara, A. E. Pekary, R. Ross, B. N. Singh, and J. J. Di Stefano III. 1986. Thyroxine and triiodothyronine kinetics in cardiac patients taking amiodarone. Acta Endocrinol. 111:193-199.

31. Yamamoto, T., K. Doi, K. Ichihara, and K. Miyai. 1980. Reevaluation of measurement of serum free thyroxine by equilibrium dialysis based on computational analysis of the interaction between thyroxine and its binding proteins. J. Clin. Endocrinol. Metab. 60:882-888.

32. Lalloz, M. R. A., P. G. H. Byfield, and R. L. H. Himsworth. 1983. Hyperthyroxinemia: abnormal binding of $T_{4}$ by an inherited albumin variant. Clin. Endocrinol. 18:11-24.

33. Isozaki, O., N. Okada, T. Tsushima, M. Saji, H. Kitahara, Y Fukuyama, and T. Tanaka. 1985. An unusual type of familial dysalbuminemic hyperthyroxinemia in a Japanese family. Ninth International Thyroid Congress, Sao Paulo, Brazil. 30a. (Abstr.)

34. Bianchi, R., G. Mariani, N. Molea, A. Pilo, F. Vitek, F. Cazzuola, M. G. Toni, M. Ferdeghini, G. Iervasi, and A. Carpi. 1984. Peripheral metabolism and interconversion of thyroid hormones in patients with thyroidal and extrathyroidal disorders of thyroid hormone metabolism. In Nuklearmedizin. H. A. E. Schimdt and D. E. Vauramo, editors. F. K. Schattauer Verlag, Stuttgart-New York. 699-702.

35. Nicoloff, J. T., J. C. Low, J. H. Dussault, and D. A. Fisher. 1972. Simultaneous measurement of thyroxine and triiodothyronine peripheral turnover kinetics in man. J. Clin. Invest. 51:473-483.

36. Refetoff, S., V. S. Fang, J. S. Marshall, and N. I. Robin. 1976. Metabolism of thyroxine-binding globulin in man. J. Clin. Invest. 57: 485-495.

37. Oppenheimer, J. H., H. L. Schwartz, and M. I. Surks. 1975. Revised calculations of common parameters of iodothyronine metabolism and distribution by non-compartmental analysis. J. Clin. Endocrinol. Metab. 41:1172-1173.

38. Hays, M. T., and R. A. Mc Guire. 1980. Distribution of subcutaneous thyroxine, triiodothyronine and albumin in man: comparison with intravenous administration using a kinetic model. J. Clin. Endo crinol. Metab. 51:1112-1117.

39. Giraudi, G., and A. Bacolla. 1983. The kinetics and mechanism of the interaction between thyroxine and serum binding proteins. In Advances in Thyroid Hormones. International Congress Series 1/83. A. Carpi, editor. Edizioni Tecnico Scientifiche, Pisa. 299-318.

40. Pardridge, W. M., and E. M. Landaw. 1984. Tracer kinetic model of blood-brain barrier transport of plasma protein-bound ligands. J. Clin. Invest. 74:745-752.

41. Shimizu, T., C. S. Pittman, Jr., J. B. Chambers, M. W. Buck, and C. C. Thurston. 1976. The effect of thyroxine on the peripheral conversion rate of thyroxine to triiodothyronine in man. In Thyroid Research. J. Robbins and L. E. Braverman, editors. Excerpta Medica, Amsterdam. 263-265.

42. Pittman, C. S. 1979. Hormone metabolism. In Endocrinology. Vol. 1. L. J. De Groot, editor. Grune \& Stratton, New York. 365-372.

43. Ingbar, S. H. 1961. Clinical and physiological observations in a 
patient with an idiopatic decrease in the thyroxine-binding globulin of plasma. J. Clin. Invest. 43:2053-2063.

44. Cavalieri, R. R., M. Steinberg, and G. L. Searle. 1970. The distribution kinetics of triiodothyronine: studies of euthyroid subjects with decreased plasma thyroxine-binding globulin and patients with Graves' disease. J. Clin. Invest. 49:1041-1050.

45. Sakurada, T., T. Yamaguchi, K. Yoshida, M. Yamamoto, S. Onodera, and S. Saito. 1974. Kinetics of thyroxine and triiodothyronine in a case of thyroxine-binding deficiency with hypothyroidism. Tohoku J. Exp. Med. 112:133-140.

46. Kaptein, E. M., D. A. Grieb, C. A. Spencer, W. S. Wheeler, and J. T. Nicoloff. 1981. Thyroxine metabolism in the low thyroxine state of critical nonthyroidal illness. J. Clin. Endocrinol. Metab. 53:764-771.
47. Hennemann, G., R. Docter, and A. Dolman. 1971. Relationship between total thyroxine and absolute free thyroxine and the influence of absolute free thyroxine on thyroxine disposal in humans. J. Clin. Endocrinol. Metab. 33:63-67.

48. Premachandra, B. N., I. K. Williams, B. C. Nisula, and J. Wortsman. 1985. Enhanced rate of cellular uptake of thyroxine $\left(T_{4}\right)$ from sera of subjects with familial dysalbuminemic hyperthyroxinemia (FDH). Ninth International Thyroid Congress, Sao Paulo, Brazil. 31a. (Abstr.)

49. Giraudi, G. 1984. Hormone-binding protein interactions: part I. J. Clin. Immunoassay. 7:268-273.

50. Giraudi, G. 1984. Hormone-binding protein interactions: part II. J. Clin. Immunoassay. 8:63-72. 